\title{
Türkçe Metinlerde Makine Öğrenmesi Algoritmalarının Duygu Analizi Problemi Üzerindeki Performansının Kıyaslanması
}

\author{
Ayşe Berna Altınel ${ }^{1 *}$

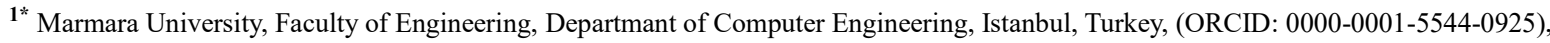 \\ berna.altinel@marmara.edu.tr
}

(1st International Conference on Applied Engineering and Natural Sciences ICAENS 2021, November 1-3, 2021)

(DOI: $10.31590 /$ ejosat.1011864)

\begin{abstract}
ATIF/REFERENCE: Altınel, A. B. (2021). Türkçe Metinlerde Makine Öğrenmesi Algoritmalarının Duygu Analizi Problemi Üzerindeki Performansının Kiyaslanması. Avrupa Bilim ve Teknoloji Dergisi, (28), 1056-1061.

$\ddot{O ̈ z}$

Günümüzde gittikçe yaygınlaşan sosyal medya kullanımı ile duygular ve fikirler bu platformlar üzerinden ifade edilmektedir. Bu platformlarda paylaşılan fikirler ile büyük miktarda veri ortaya çıkmaktadır. $\mathrm{Bu}$ verilerin sınıflandırılmasının ve analizinin manuel olarak yapılması büyük bir iş gücü gerektirdiğinden bazı algoritmalar ile duygu analizi yapılması gereksinimi ortaya çıkmıştır. Bu çalışmada çeşitli platformlardan alınan beş farklı veri kümesi ve her bir veri kümesi için dört farklı makine öğrenmesi algoritması(KNN, Naif Bayes, Rastgele Orman, DVM) kullanılmıştır. Çalışma sonucunda DVM algoritması ile veri setlerinin genelinde daha doğru sonuçlar, Rastgele Orman ve Naif Bayes algoritmaları ile veri setleri ve eğitim yüzdelerine göre değişken sonuçlar elde edilmiştir. KNN algoritması ile veri setlerinin genelinde doğruluğu en düşük sonuçlar elde edilmiştir.
\end{abstract}

Anahtar Kelimeler: Duygu Analizi, Makine Öğrenmesi, Sosyal Medya Analizi, Sınıflandırma, Metin madenciliği.

\section{Comparison of the Performance of Machine Learning Algorithms on Sentiment Analysis Problem in Turkish Texts}

\begin{abstract}
Recently, with the use of social media, which is becoming more and more widespread today, emotions and ideas are expressed through these platforms. Huge amounts of data emerge with ideas shared on these platforms. Since the classification and analysis of these data requires a large labor force, the need for sentiment analysis with some algorithms has emerged. In this study, five different datasets from various platforms and four different machine learning algorithms (kNN, Naive Bayes, Random Forest, SVM) were used for each dataset. As a result of the study, more accurate results were obtained in general with the SVM algorithm, and variable results were obtained with the Random Forest and Naive Bayes algorithms according to the data sets and training percentages. With the KNN algorithm, the lowest accuracy results were obtained across the data sets.
\end{abstract}

Keywords: Sentiment Analysis, Machine Learning, Social Media Analysis, Classification, Text Mining.

\footnotetext{
* Corresponding Author: berna.altinel@marmara.edu.tr
} 


\section{Giriş}

Duygu analizi (Sentiment Analysis), herhangi bir metin yazarının görüşlerini, duygularını ve tutumlarını anlamak için kullanılan bir çalışma alanıdır. Duygu analizinde, metin belirli cümlelere veya kelimelere bölünerek analiz edilir ve metnin içeriği olumlu, olumsuz veya nötr olarak sınıflandırılır. Duygu analizinde, yazarın herhangi bir ürün, olay, kişi veya fikir hakkında ifade ettiği görüşleri analiz etmek amaçlanır.

Sosyal medya araçları insanların farklı sosyal medya kanalları aracılığıyla ürünler, toplumsal ve politik olaylar, farklı fikirler, düşünceler hakkında yorum ve değerlendirme yapabilmesi, bunlara internet erişimi olan herkesin kolayca erişebilmesi, metin ve duygu analizi için işlenmemiş bir veri kaynağıdır.

Sosyal medyanın ortaya çıkarttığı bu verileri kullanarak kullanıcıların daha iyi bir sosyal medya deneyimi geçirmesi, isteklerine göre şekillenen bir sosyal medya profili oluşturulması hedeflenebilir. $\mathrm{Bu}$ hedefler Facebook ve Twitter gibi büyük firmalar için çok önemli bir özellik haline gelmiştir. Yine bu ham verilerden ortaya çıkacak bilgi, pazarlama sektörü için de çok önemlidir. Reklam firmaları bu bilgileri kullanarak kullanıcın isteklerine göre reklam göstermeyi hedeflemişlerdir. Buna ek olarak firmalar ürünleri için kullanıcılardan tarafından yapılan olumlu, olumsuz veya nötr yorumlar sayesinde performans analizi yapabilir ya da ürünlerinin eksik yönlerini tespit edebilirler. $\mathrm{Bu}$ sayede ürünlerini kullanıcıların isteklerine göre geliştirebilirler. Sonuç olarak birçok sektör sosyal medyanın çıkarttığı bu ham verinin işlenmesinin peşine düşmüştür. Günümüzde bilgi en pahalı ürüne dönüşmüştür.

$\mathrm{Bu}$ veriler gerçek toplum hakkında bilgi edinebilmek için üreticiler, politikacılar, sosyal bilimciler ve diğer insan ve toplumu ele alan araştırmalarda çok değerli olabilmektedir. $\mathrm{Bu}$ platformlarda ortaya çıkan ve gün geçtikçe artan ham veri yığınları bu amaçlar için kullanılmaya hazır değildir. Duygu analizi ile veriler amaca uygun olarak işlenebilir ve bahsedilen araştırmalar için değerli hale getirilebilir.

Duygu analizi çalışmaları yapılırken, metinlerin olumlu, olumsuz ya da nötr içeriğe sahip olup olmadığına bakılır ve analiz edilir. Analizin sonucunda; metinlerin konusu dahilinde, insanların bu konu hakkındaki düşünceleri belirlenir. Dolayısıyla hem hali hazırda üretilmiş ürünler hakkında insanların düşünceleri öğrenilebilir; hem de henüz piyasaya çıkmamış bir ürünün insanlar tarafından nasıl değerlendirilebileceği, sevilip sevilmeyeceği, ne tarz tepkilerle karşılaşılabileceği konusunda fikir sahibi olunabilir.

Verilerin anlamlı hale getirilebilmesi için bilinen birçok yöntem vardır. Manuel veya bir algoritma yardımı ile sınıflandırma yapılabilir. Manuel sınıflandırma yapmak yüksek iş gücü ve zaman kaybı ortaya çıkarabilmektedir. Makine öğrenmesi algoritmaları, daha kısa sürede, daha az iş gücü ile doğruluğu yüksek işlenmiş veri kümeleri oluşturulabilir.

\section{Literatür Taraması}

$\mathrm{Bu}$ kısımda metin ve duygu analizi ile ilgili daha önce yapılmış çalışmalara yer verilmektedir.

Kaynar O. vd. yapmış oldukları çalışmada duygu analizinde öznitelik düşürme yöntemlerinin oto kodlayıcı derin öğrenme makinaları ile karşılaştırılması yapılmıştır. Metin analizinde frekansı düşük olan kelimelerin cümle vektörlerinde bolca sıfır verisi bulundurması makine öğrenme algoritmalarının verimini düşürdüğü için boyut küçültme uygulanmıştır. Doğrusal ve doğrusal olmayan gözetimsiz makine öğrenmesi tabanlı boyut düşürme algoritmaları kullanılmıştır. IMDB film yorumları veri seti 1000 pozitif ve 1000 negatif yorum olacak şekilde dengeli olarak ayrılmıştır. Kullanılan kütüphane olarak her bir kelimenin kökleri NLTK kütüphanesi yardımıyla bulunmuştur. Deney sonucunda boyut düşürme teknikleri uygulanan veri setlerinden daha yüksek başarı elde edilmiştir. Boyut düşürme yöntemleri (TDA, TBA, çTBA, FA) uygulanmadan makine öğrenme algoritmaları (DVM, YSA) kullanılan sonuç ile boyut düşürme yöntemleri uygulanarak yapılan sonuç ile karşılaştırma yapılmıştır (Kaynar ve ark., 2019).

Akgül E. vd. yapmış olduğu çalışmada Twitter verileri ile duygu analizi yapılmıştır. Duygusal Twitter adındaki bu çalışmada bir anahtar kelime belirlenerek her bir tweete ait duygu analizi olumlu, olumsuz veya nötr olarak etiketlenmeye çalışılmış, bu sayede bir sözlük elde edilmesi amaçlanmıştır. Sözlük ve n-gram olmak üzere iki adet farklı yöntem kullanılmıştır. Tarafsız bakış açısı yakalayabilmek adına belirlenen iki kişi tweetleri olumlu, olumsuz veya nötr şeklinde etiketlenmiştir. Daha sonra veri setlerinden duygu analizi için gereksiz karakterler temizlenmiş, kelimelerin tekrar sayısı ile frekansları bulunup, her veri seti için farklı kelime frekansları hesaplanmıştır. N-gram modelinde ise 2, 3 ve 4 gramlar kullanılarak sistem ayrı ayrı test edilmiştir. Deney sonuçlarında en fazla başarı en çok tweet sayısına sahip VS3 veri setinden alınmıştır. 3 farklı veri seti 2 farklı etiketleme yöntemiyle karşılaştırılmıştır (Akgül ve ark., 2016).

Tuzcu S. yaptığı çalışmada Türkçe çevrimiçi kullanıcı yorumlarının yüksek doğrulukla yönlü sınıflandırılması yapılmak istenmiştir. Python programlama dili ve rapid miner üzerinde veri ön işleme, makine öğrenmesi yöntemlerinin uygulanması gerçekleştirilmiştir. Veri ön işleme işleme için NLTK kütüphanesi kullanılmıştır. Çalışmada MLP, NB, DVM, LR makine öğrenmesi yöntemleri aynı veri seti üzerinde sınıflandırma başarılarına göre karşılaştırılmıştır. Bu karşılaştırma sonucunda MLP pozitif ve ortalama sınıflandırma başarısında ön plana çıkmış, NB ise diğer yöntemlere göre negatif sinıflandırmada pozitife göre daha başarılı sonuç vermiştir (Tuzcu, 2020).

Aytekin Y. E. ve Keskin Ö. yapmış oldukları çalışmada faizsiz finans sistemi ile ilgili türkçe metinler üzerinden duygu analizi yöntemi ile potansiyel müşterilerin faizsiz finans sitemine yönelik pozitif ve negatif algıları anlaşılmak istenmiştir. Veri seti 2019 Ocak ayına ait faizsiz finans sistemi ile ilgili türkçe metinlerden oluşmaktadır. Bu metinler sosyal medya ve internet kaynaklarına aittir. $\mathrm{Bu}$ çalışmada teknik herhangi bir ayrıntı paylaşılmamıştır. Çalışmada analiz kısmı www.mediatoolkit.com adresinde bulunan çevrimiçi program ile yapılmıştır. Yazarların vardığ 1 sonuç şu: "İslami temellere dayanan faizsiz finans sistemindeki kurumlar, sömürü mantığıyla ortaya çıkan konvansiyonel rakiplerinden; üretimi, paylaşımı ve ahlaki değerleri ön planda tutacak şekilde ayrışmalıdır. Bu farklılığın göstergesi olarak en azından "banka" terimi yerine "finans" teriminin kullanılması daha doğru olacaktır." doğrudan alıntılanmıştır (Aytekin ve Keskin, 2019).

Eryılmaz vd. yapmış oldukları çalışmada reklam, alakasız içerik barındıran ve kişiye zarar veren yaramaz epostaların makine öğrenmesi yöntemleri ile tespiti amaçlanmıştır. 2 tane 
Türkçe veri seti kullanılmıştır. Bunlardan biri "TurkishEmail" veri kümesi diğeri ise yazarlar tarafından hazırlanan "TrHamSpamEmailv1.0" veri setidir. İlk olarak veri setlerinde öznitelik çıkarımı ve özellik seçimi yapılmıştır. Veri setlerinde çalışılan makine öğrenme algoritmaları RF, C4.5 karar ağacı, SMO, KNN, LR, NB, MLP'dir. Veri kümeleri ön işlemden geçerken işleme tabii tutulan her sözcük Türkçe doğal dil işleme kütüphanesi olan "Zemberek" yazılımından geçirilip köklerine ayrıştırılmıştır. Elde edilen sonuçlara göre \%98'in üzerinde bir orana kadar yaramaz e-postaların filtrelenebildiği görülmüştür (Eryılmaz ve ark., 2020).

Demir vd. yapmış oldukları çalışmada büyük miktardaki Türkçe metin verilerini kısa zaman içerisinde otomatik olarak analiz etmeyi amaçlamışlardır. Yani yapısal olmayan veri kaynaklarının analizini yaparak, yapısallaştırılmış veri elde etmeyi amaçlamışlardır. Geliştirdikleri uygulama kelime düzeyinde çalışmaktadır. Toplam 3 farklı veri setinden yararlanmışlardır. Bunlardan ilki yaklaşık 5000, ikincisi ve üçüncüsü ise yaklaşık 25000 adet kelime içermektedir. Toplamda yaklaşık olarak 55000 adet kelimeden faydalanmışlardır. Araştırmacılar Afinn, Bing, Nrc ve Sentitürk sözlüklerini bir araya getirip değerlendirerek duygu analizi yapmayı hedeflemişlerdir. Araştırmacılar çalışmalarında iki farklı yöntem kullanmışlardır. Bunlardan ilki, veri setleri için sırasıyla \%77,14, $\% 72,78, \% 74,17$ doğruluk oranına sahiptir. İkinci yöntemde ise aynı veri setleri için sırasıyla \%82,85, \%74,92, \%77,50 doğruluk oranına sahiptir. Toplamda ilk yöntem $\% 74,11$ doğruluk oranına sahipken, ikinci yöntem \%77,445 doğruluk oranına sahiptir. Yazarlar bu çalışmasında bu alanda yapılmış olan çalışmalara bir yenisini daha ekleyip, bu alanın gelişmesinde katkıda bulunmak amacını da gütmüşlerdir (Demir ve ark., 2020).

\section{Yöntem}

Duygu analizi (veya fikir madenciliği), verilerin olumlu, olumsuz veya tarafsız olup olmadığını belirlemek için kullanılan bir doğal dil işleme tekniğidir. Duyarlılık analizi, işletmelerin müşteri geri bildirimlerinde marka ve ürün duyarlılığını izlemelerine ve müşteri ihtiyaçlarını anlamalarına yardımcı olmak için genellikle metin tabanlı veriler üzerinde gerçekleştirilmektedir. $\mathrm{Bu}$ amaçla duyarlılık analizi için farklı ögrenme modelleri kullanılmaktadır (Demir ve ark., 2020). Bu çalışmada kullanılan modeller bu bölümde daha ayrıntılı olarak ele alınmıştır.

\subsection{KNN (K-En Yakın Komşu)}

KNN algoritması temel olarak, sinıflandırılmak istenen bir veriyi daha önceki verilerle olan komşuluk ilişkisine göre sinıflandıran bir algoritmadır. KNN ile yeni noktaya en yakın noktalar aranır. K tane, bilinmeyen noktanın en yakın komşularını temsil eder (Sutton, 2012). Analitik olarak izlenebilir olmas1, yerel bilgilere uyarlanabilir olması, tutarsız eğitim verilerine karşı dirençli olması KNN algoritmasının avantajlarındandır. KNN algoritmasının dezavantajlarına yüksek miktarda bellek alanlarına ihtiyaç duyması, veri seti boyutu arttıkça işlem yükünün artması örnek gösterilebilir.

https://www.analyticsvidhya.com/blog/2018/03/introduction-kneighbours-algorithm-clustering/

https://en.wikipedia.org/wiki/Random_forest

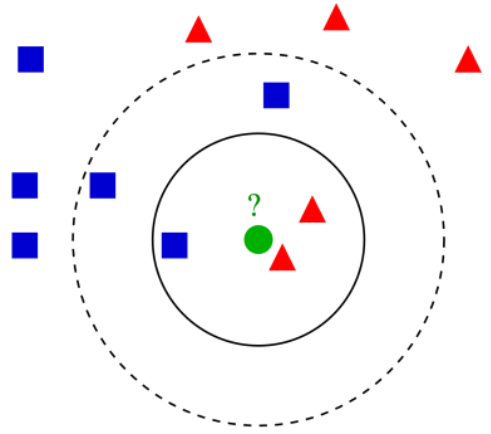

\section{Şekil 1. KNN algoritması sınıflandırma örneği ${ }^{1}$}

Şekil 1' de örnek bir KNN sınıflandırması gösterilmiştir. Şekildeki yeşil nokta, mavi karelere veya kırmızı üçgenlere göre sınıflandırılmaktadır. Şekil 1'de $\mathrm{K}=3$ olduğu durumda, daire içerisindeki duruma bakılır. Kırmızı üçgenlerin sayısı mavi karelerden fazla olacağından sınıflandırma kırmızı üçgenlere göre yapılır. Ancak $\mathrm{K}=5$ olduğu durumda, kesikli daire içerisindeki duruma bakılır ve kırmızı üçgenlerin sayısı mavi karelerden daha az olduğundan sınıflandırma mavi karelere göre yapılır (Arroyo ve ark., 2009).

\subsection{Naif Bayes}

Naif Bayes yöntemi, değişkenlerinin değeri verilen her özellik çifti arasında koşullu bağımsızlık varsayımıyla uygulanmasına yönelik bir dizi denetimli öğrenme algoritmasıdır (Zhang, 2004). Naif Bayes modelinin kullanımı kolaydır ve büyük veri kümeleri için kullanışlı olup karmaşık sınıflandırma yöntemlerine kıyasla daha verimli olduğu bilinmektedir. Şekil 2'de Bayes Teoreminin sonlu olasılık denklemi gösterilmektedir.

$$
P(c \mid x)=(P(x \mid c) P(c)) /(P(x))
$$

Denklem (1)' de $P(c \mid x)$ sonlu olasılığ,$P(x \mid c)$ verilen sınıfın tahmin edicisinin olasılığ olan olabilirliktir. $P(x)$ tahmin edicinin önceki olasılığını ifade etmektedir (Shah ve ark., 2020).

\subsection{Rassal Orman}

Rassal Orman, davranış analizinde tahminleri modellemede kullanılan bir tekniktir ve karar ağaçları üzerine kuruludur. Bir dizi regresyon karar ağacının sonuçlarını birleştirerek çıktı tahminleri yapan makine öğrenmesi modelidir (Williams ve ark., 2020). Her ağaç bağımsızdır ve ormandaki tüm ağaçlar aynı dağılıma sahip olup, girdi verilerinden örneklenen rastgele vektöre bağlıdır (Breiman, 2001). Rassal Orman algoritması her ağacın rastgele vektör değerlerine bağlı olduğu bir ağaç tahmincisi görevi görür. Büyük verileri sınıflandırmak için en iyi algoritmalardan bir tanesidir.

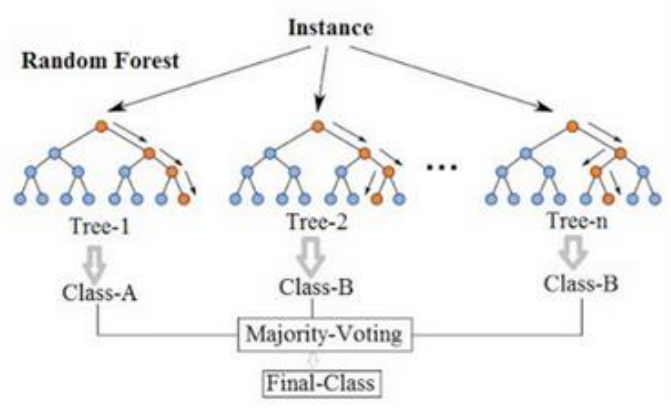

Şekil 2. Rassal Orman modeli için örnek bir karar şeması ${ }^{2}$

Şekil 2'de üç adet karar ağacı gösterilmiştir. Bir karar ağacında, en üstte bir girdi girilmekte ve ağaçta aşağıya inildikçe veriler daha küçük kümeler halinde toplanmaktadır. Tek bir karar ağacına güvenmek yerine her ağaçtan tahmin alınmakta ve 
tahminlerin çoğunluk oylarına göre sonuç çıktısı tahmin edilmektedir.

\subsection{DVM (Destek Vektör Makinesi)}

DVM sınıflandırma ve regresyon problemleri için kullanılan bir makine öğrenmesi modelidir. Öncelikli olarak sınıflandırma problemleri için kullanılmaktadır. DVM, yeni veri noktasını kolayca tespit edebilmek için n-boyutlu uzayı sınıflara ayırabilen en iyi çizgi veya karar sınırını oluşturmaktadır. Bu en iyi karar sınırına hiperdüzlem denmektedir. DVM, hiper düzlemi oluşturmaya yardımcı olan vektörleri seçmekte ve "Destek Vektör Makinesi" olarak adlandırılmaktadır (Platt, 1999).

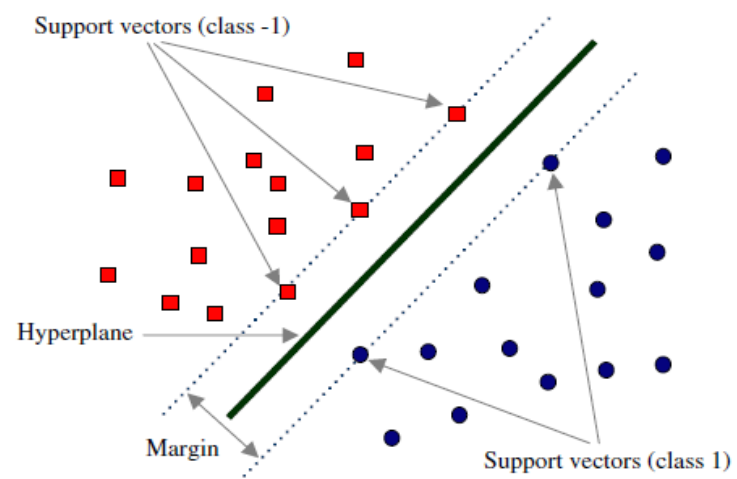

Şekil 3. Destek vektör makinelerinin küme ayrışımını temsil etmekte $^{1}$

Şekil 3'te bir karar sınırı veya hiperdüzlem kullanılarak sınıflandırılan iki farklı kategorinin bulunduğu görülmektedir.

Yüksek boyutlu uzaylarda etkili kümeleme yapması ve belleği daha etkin kullanması DVM'in avantajları arasındadır.

Boyutların sayısının örnek sayısından fazla olduğu durumlarda DVM daha etkili olmaktadır. Ancak büyük veri kümeleri için uygun değildir. Veri kümesine oranla gürültü (signal-to-noise ratio) oranı arttıkça DVM sınıflandırma performansı düşmektedir (Lin ve Chang, 2001).

\section{Deney Ortamı ve Deney Sonuçları}

\subsection{Deney Ortamı}

Bu çalışmada beş farklı veri set üzerinde, dört farklı makine öğrenmesi modeli ile duygu analizi yapılmıştır. İlk veri kümesi turizm başlığı altında atılan toplam 4202 tweet'ten oluşmaktadır. $\mathrm{Bu}$ veriler olumlu ve olumsuz olmak üzere 2 sinıfa ayrılmıştır. İkinci veri kümesi satın alınan ürünler hakkında yapılan yorumlardan oluşmakta ve olumlu, olumsuz ve tarafsız olarak sınıflara ayrılmıştır. Toplam 8492 adet mağaza yorumuna ait duygu ifadelerini içermektedir. Üçüncü veri kümesi satın alınan ürünler hakkında yapılan yorumlardan oluşmakta ve olumlu, olumsuz ve tarafsız olarak sınıflara ayrılmıştır. Toplam 11430 adet ürün yorumlarının duygu ifadesi içermektedir. Dördüncü veri kümesi çeşitli blog yazarlarının neşeli, sinirli, üzgün, karışık olmak üzere 4 farklı sınıfta incelendiği toplamda 157 blog yazısı içermektedir. Beşinci veri kümesi kullanıcıların izledikleri film hakkında yapılan yorumlardan oluşmakta ve pozitif, negatif ve tarafsız olarak sınıflara ayrılmıştır. Her sınıfta 35'er adet olmak üzere toplamda 105 adet film yorumu bulunmaktadır.

\footnotetext{
https://www.researchgate.net/figure/Classification-of-data-by-
} support-vector-machine-SVM_fig8_304611323.
$\mathrm{Bu}$ çalışmada Veri depolama işlemleri için mongodb kullanılmıştır. Veri işleme işlemleri ise Spyder programı üzerinden python programlama dili kullanılarak gerçekleştirilmiştir. Çalışmada kullanılan yardımcı kütüphaneler: pymongo, sklearn, zemberek'den oluşmaktadır. Mongodb üzerinden veri alışverişi için pymongo, veriler üzerinde kullanılan algoritmalar için sklearn ve verilerin Türkçe doğal dil işlemleri için Zemberek kullanılmıştır.

\subsection{Deney Sonuçları}

Turizm veri kümesi üzerinde algoritmaların F1 puan yüzdeleri (F1-score) Tablo 1'de gösterilmektedir. Deney sonuçlarına göre DVM algoritması tüm deneylerde diğer algoritmalara kıyasla en yüksek sonuçları vermiştir. Örneğin DVM algoritmasının \%30 eğitim- $\% 70$ test seti, $\% 40$ eğitim- $\% 60$ test seti, $\% 50$ eğitim- $\% 50$ test seti ve $\% 70$ eğitim- $\% 30$ test seti üzerindeki $\mathrm{F} 1$ puan yüzdeleri (F1-score) sirasiyla \%86.93, \%87.55, \%88.14 ve \%89.09'dır.

Tablo 1. Turizm veri kümesi üzerinde algoritmaların F1 puan yüzdeleri (F1-score)

\begin{tabular}{|l|c|c|c|c|}
\hline Algoritma & $\begin{array}{l}\text { \%30 } \\
\text { eğitim- } \\
\mathbf{\% 7 0} \\
\text { test }\end{array}$ & $\begin{array}{l}\mathbf{\% 4 0} \\
\text { eğitim- } \\
\mathbf{\% 6 0} \\
\text { test }\end{array}$ & $\begin{array}{l}\mathbf{\% 5 0} \\
\text { eğitim- } \\
\mathbf{\% 5 0} \\
\text { test }\end{array}$ & $\begin{array}{l}\mathbf{\% 7 0} \\
\text { eğitim- } \\
\mathbf{\% 3 0} \\
\text { test }\end{array}$ \\
\hline $\begin{array}{l}\text { Rassal Orman } \\
\text { (RandomForest) }\end{array}$ & 83.88 & 84.02 & 84.11 & 84.52 \\
\hline $\begin{array}{l}\text { Naif Bayes } \\
\text { (Naive Bayes) }\end{array}$ & 79.64 & 80.12 & 80.22 & 81.17 \\
\hline $\begin{array}{l}\text { K-En Yakın } \\
\text { komşuluk(KNN) }\end{array}$ & 68.82 & 70.46 & 71.14 & 71.34 \\
\hline DVM(SVM) & 84.59 & 84.73 & 84.90 & 85.42 \\
\hline
\end{tabular}

Mağaza veri kümesi üzerinde algoritmaların F1 puan yüzdeleri (F1-score) Tablo 2'de gösterilmektedir. Deney sonuçlarına göre DVM algoritması tüm deneylerde Rassal Orman, Naif Bayes ve K-En Yakın komşuluk algoritmalarına kıyasla en yüksek sonuçları vermiştir.

Tablo 2. Mağaza veri kümesi üzerinde algoritmaların F1 puan yüzdeleri (F1-score)

\begin{tabular}{|l|c|c|c|c|}
\hline Algoritma & $\begin{array}{l}\text { \%30 } \\
\text { eğitim- } \\
\text { \%70 } \\
\text { test }\end{array}$ & $\begin{array}{l}\text { \%40 } \\
\text { eğitim- } \\
\mathbf{\% 6 0} \\
\text { test }\end{array}$ & $\begin{array}{l}\mathbf{\% 5 0} \\
\text { eğitim- } \\
\mathbf{\% 5 0} \\
\text { test }\end{array}$ & $\begin{array}{l}\text { \%70 } \\
\text { eğitim- } \\
\mathbf{\% 3 0} \\
\text { test }\end{array}$ \\
\hline $\begin{array}{l}\text { Rassal Orman } \\
\text { (RandomForest) }\end{array}$ & 67.81 & 68.21 & 69.17 & 69.84 \\
\hline $\begin{array}{l}\text { Naif Bayes } \\
\text { (Naive Bayes) }\end{array}$ & 74.62 & 75.54 & 76.52 & 77.30 \\
\hline $\begin{array}{l}\text { K-En Yak1n } \\
\text { komşuluk(KNN) }\end{array}$ & 58.01 & 59.90 & 60.53 & 61.37 \\
\hline DVM(SVM) & 86.93 & 87.55 & 88.14 & 89.09 \\
\hline
\end{tabular}

Ürün veri kümesi üzerinde algoritmaların F1 puan yüzdeleri (F1-score) Tablo 3'te gösterilmektedir. Deney sonuçlarına göre en yüksek F1 puan yüzdelerini veren algoritmalar sırasıyla DVM algoritması, Rassal Orman, Naif Bayes ve K-En Yakın komşuluk algoritmaları şeklindedir. 
Tablo 3. Ürün veri kümesi üzerinde algoritmaların F1 puan yüzdeleri (F1-score)

\begin{tabular}{|l|c|c|c|c|}
\hline Algoritma & $\begin{array}{l}\text { \%30 } \\
\text { eğitim- } \\
\mathbf{\%} 70 \\
\text { test }\end{array}$ & $\begin{array}{l}\text { \%40 } \\
\text { eğitim- } \\
\mathbf{\%} 60 \\
\text { test }\end{array}$ & $\begin{array}{l}\mathbf{\% 5 0} \\
\text { eğitim- } \\
\mathbf{\%} 50 \\
\text { test }\end{array}$ & $\begin{array}{l}\text { \%70 } \\
\text { eğitim- } \\
\mathbf{\% 3 0} \\
\text { test }\end{array}$ \\
\hline $\begin{array}{l}\text { Rassal Orman } \\
\text { (RandomForest) }\end{array}$ & 75.90 & 78.35 & 79.03 & 81.52 \\
\hline $\begin{array}{l}\text { Naif Bayes } \\
\text { (Naive Bayes) }\end{array}$ & 72.47 & 74.98 & 76.37 & 78.71 \\
\hline $\begin{array}{l}\text { K-En Yakın } \\
\text { komşuluk(KNN) }\end{array}$ & 57.81 & 58.05 & 58.42 & 58.61 \\
\hline DVM(SVM) & 87.02 & 87.84 & 88.51 & 88.61 \\
\hline
\end{tabular}

Tablo 4 ise Blog veri kümesi üzerindeki algoritmaların F1 puan yüzdelerini (F1-score) göstermektedir. Deney sonuçlarına göre örneğin \%30 eğitim-\%70 test setinde DVM algoritmas1, Rassal Orman, Naif Bayes ve K-En Yakın komșuluk algoritmalarının aldıkları F1 puan yüzdeleri (F1-score) sirasiyla \%67.13, \%69.15, \%54.72ve \%74.40’dır. Tablo 4. Blog veri kümesi üzerinde algoritmaların F1 puan
yüzdeleri (F1-score)

\begin{tabular}{|l|c|c|c|c|}
\hline Algoritma & $\begin{array}{l}\text { \%30 } \\
\text { eğitim- } \\
\mathbf{\% 7 0} \\
\text { test }\end{array}$ & $\begin{array}{l}\mathbf{\% 4 0} \\
\text { eğitim- } \\
\mathbf{\%} 60 \\
\text { test }\end{array}$ & $\begin{array}{l}\mathbf{\% 5 0} \\
\text { eğitim- } \\
\mathbf{\% 5 0} \\
\text { test }\end{array}$ & $\begin{array}{l}\text { \%70 } \\
\text { eğitim- } \\
\text { \%30 test }\end{array}$ \\
\hline $\begin{array}{l}\text { Rassal Orman } \\
\text { (RandomForest) }\end{array}$ & 67.13 & 68.32 & 69.20 & 70.35 \\
\hline $\begin{array}{l}\text { Naif Bayes } \\
\text { (Naive Bayes) }\end{array}$ & 69.15 & 70.69 & 71.47 & 72.23 \\
\hline $\begin{array}{l}\text { K-En Yakin } \\
\text { komşuluk(KNN) }\end{array}$ & 54.72 & 57.79 & 58.17 & 58.43 \\
\hline DVM(SVM) & 74.40 & 75.14 & 76.50 & 77.41 \\
\hline
\end{tabular}

Film veri kümesi üzerinde algoritmaların F1 puan yüzdeleri (F1-score) Tablo 5'te gösterilmektedir. Deney sonuçlarına göre DVM algoritması tüm deneylerde Rassal Orman, Naif Bayes ve K-En Yakın komşuluk algoritmalarına kıyasla en yüksek sonuçları vermiştir.

Tablo 5. Film veri kümesi üzerinde algoritmaların F1 puan yüzdeleri (F1-score)

\begin{tabular}{|l|l|l|l|l|}
\hline Algoritma & $\begin{array}{l}\text { \%30 } \\
\text { eğitim- } \\
\mathbf{\% 7 0} \\
\text { test }\end{array}$ & $\begin{array}{l}\text { \%40 } \\
\text { eğitim- } \\
\mathbf{\% 6 0} \\
\text { test }\end{array}$ & $\begin{array}{l}\mathbf{\% 5 0} \\
\text { eğitim- } \\
\mathbf{\% 5 0} \\
\text { test }\end{array}$ & $\begin{array}{l}\mathbf{\% 7 0} \\
\text { eğitim- } \\
\mathbf{\% 3 0} \\
\text { test }\end{array}$ \\
\hline $\begin{array}{l}\text { Rassal Orman } \\
\text { (RandomForest) }\end{array}$ & 67.21 & 67.63 & 68.13 & 68.52 \\
\hline $\begin{array}{l}\text { Naif Bayes } \\
\text { (Naive Bayes) }\end{array}$ & 64.65 & 65.14 & 66.46 & 67.71 \\
\hline $\begin{array}{l}\text { K-En Yakın } \\
\text { komşuluk }(\text { KNN) }\end{array}$ & 59.03 & 59.86 & 61.27 & 61.87 \\
\hline DVM(SVM) & 77.56 & 78.61 & 79.03 & 80.18 \\
\hline
\end{tabular}

\section{Sonuçlar}

Bu çalışmada, 5 farklı veri seti üzerinde 4 farklı makine öğrenmesi algoritması ile bir çalışma yapılmıştır. Bu çalışmanın amacı dört farklı algoritma arasındaki davranışsal farklılıkları tespit etmek ve gözlemlemektir. Kullanılan makine öğrenmesi algoritmalarının varsayılan parametrelerinin üzerinde değişiklik yapılmamıştır. Yapılan çalışmadaki algoritmaların verdikleri F1 puanlarına (F1 score) yüzdelerine bakıldığında en optimal algoritmanın DVM algoritması olduğu görülmüştür. Genel olarak verinin az olduğu veri setlerinde dört algoritmanın da verdiği doğruluk oranı düşüş gözlemlenmiştir. Bu çalışmadaki veri setleri üzerindeki eğitim- test oranının en optimal hali ise \%70 eğitim$\% 30$ test olarak bulunmuştur. En kötü durum olarak ise \%30 eğitim- \%70 test olarak gözlemlenmiştir. Tüm veri kümelerinde DVM algoritması diğer algoritmalara göre daha yüksek, KNN algoritması ise daha düşük doğrulukta sınıflandırma başarısına sahip olmuştur. Rassal Orman ve Naif Bayes algoritmaları ise DVM'ye yakın sonuçlar vermişlerdir. Ek olarak gözetimli öğrenme modelleri olan DVM, Rassal Orman ve Naif Bayes algoritmaları, gözetimsiz öğrenme modeli olan KNN'e göre daha başarılı olmuştur.

\section{Teşekkür}

$\mathrm{Bu}$ çalışma kısmen 118E315 numaralı ve 120E187 numaralı araştırma projeleri aracılığıyla Türkiye Bilimsel ve Teknolojik Araştırma Kurumu (TÜBİTAK) tarafından desteklenmektedir. Bu belgedeki görüşler yazarlara aittir ve TÜBİTAK'ın resmi pozisyonunu veya politikalarını temsil etmeyebilir.

\section{Kaynakça}

Akgül, E. S., Ertano, C., Diri, B. (2016). Twitter verileri ile duygu analizi," Pamukkale University Journal of Engineering Sciences, 22(2).

Arroyo, J, and Carlos, M. (2009). Forecasting histogram time series with k-nearest neighbours methods." International Journal of Forecasting 25(1), 192-207.

Aytekin, Y. E., Keskin, Ö. (2019). Türkiye'de Faizsiz Finans Sisteminin Duygu Analizi Bağlamında Değerlendirilmesi," Uluslararası İslam Ekonomisi ve Finansı Araştırmaları Dergisi, 5(3), 87-112.

Breiman, (2001). Random Forests, Machine Learning, 1,5-32.

Demir, Ö., Chawai, A. I. B., \& Doğan, B. Türkçe Metinlerde Sözlük Tabanli Yaklaşimla Duygu Analizi Ve Görselleştirme (2020). International Periodical of Recent Technologies in Applied Engineering, 1(2), 58-66.

Eryılmaz, E. E., Şahin, D. Ö., Kılıç, E. (2020). Türkçe İstenmeyen E-postaların Farklı Öznitelik Seçim Yöntemleri Kullanılarak Makine Öğrenmesi Algoritmaları ile Tespit Edilmesi," Türkiye Bilişim Vakfı Bilgisayar Bilimleri ve Mühendisliği Dergisi, 13(2), 57-77.

Kaynar, O., Aydın, Z., Görmez, Y. (2019). Sentiment analizinde öznitelik düşürme yöntemlerinin oto kodlayıcılı derin öğrenme makinaları ile karşılaştırılması, Bilişim Teknolojileri Dergisi, 10(3), 319-326.

Lin, C. J., Chang, C. C. (2001). LIBSVM: a library for support vector machines.

Platt, J. (1999). Probabilistic outputs for support vector machines and comparisons to regularized likelihood methods, Advances in large margin classifiers, 10(3), 61-74.

Shah, K., Patel, H., Sanghvi, D., Shah, M. (2020). A comparative analysis of logistic regression, random forest and $\mathrm{KNN}$ 
models for the text classification, Augmented Human Research, 5(1), 1-16.

Tuzcu, S. (2020). Çevrimiçi Kullanıcı Yorumlarının Duygu Analizi ile Sınıflandırılması," Eskişehir Türk Dünyası Uygulama ve Araştırma Merkezi Bilişi̧ Dergisi, 1(2), 1-5.

Williams, B. Halloin, C. Löbel, W., Finklea, F., Lipke, E., Zweigerdt, R., Cremaschi, S. (2020). Data-Driven Model Development for Cardiomyocyte Production Experimental Failure Prediction", 48, 1639-1644.

Zhang, H. (2004). The Optimality of Naive Bayes, Conference: Proceedings of the Seventeenth International Florida Artificial Intelligence Research Society Conference. 